\title{
Editorial
}

\section{Do we need a "three-star" hospital to cure a gastric cancer?}

\author{
YASUHIRO KODERA \\ Department of Surgery II, Nagoya University Graduate School of Medicine, 65 Tsurumai-cho, Showa-ku, Nagoya, Aichi 466-8550, Japan
}

This editorial was written at Ostend, Belgium, where I had the honor of attending the Ninth Belgian Surgical Week. Belgian guidelines for gastric cancer treatment had just been compiled and presented at that meeting. Rather surprisingly, a D2 dissection was recommended in the guidelines as a "standard" surgical treatment "to improve staging and local disease control" [1]. As everyone knows, Belgium is adjacent to the Netherlands, where a phase III trial comparing D2 dissection with D1 was performed, only to show that the "Japanese-style" D2 procedure does not have any survival benefit $[2,3]$. How, then, could D2 be justified as a standard of care in Belgium?

When it comes to surgery, which is not simply a matter of dripping a given dose of drug at a given schedule, what has been proven in a phase III trial by one group may not hold true for another group with large differences in general medical practice. It would seem, then, as though any surgical phase III trial, however well conducted and seemingly flawless, might still leave ample room for discussion when scrutinized from another angle, and the Dutch trial is no exception. A phase III trial usually requires enrollment of a large number of patients, and this would have been an enormous burden for a small country with a relatively low incidence of gastric carcinoma. It would seem inevitable, then, that the Dutch trial was participated in by numerous institutions, the majority of which might have been so-called low-volume hospitals. In a way, we can now look back at this trial as one designed to observe what would happen when a D2 lymphadenectomy was abruptly brought into daily practice in non-specialized European community hospitals back in the 1980s. At that time, most surgeons were not familiar with either the surgical procedure or the postoperative management. The results were, indeed, what

Offprint requests to: Y. Kodera we have seen. The first report on survival data published in 1999 was disastrous for advocates of D2 surgery, with the survival curve for the D1 group going above that of the D2 group throughout the follow-up period [2].

One should be grateful to the Dutch group for the persistent follow-up. Revised data published in 2004 revealed that the survival curves crossed at 4 years postoperatively and the curve for the D2 arm eventually ended up slightly above that of the D1 arm after 10 years from surgery [3]. One cannot fail to notice, by looking closely at these curves, a steep decline in the survival curve for D2 at the very early phase of followup, apparently showing the detrimental effect of a high operative mortality. This implies the possibility, although not all would agree, that the mortality nullified a modest but infallible survival benefit of the extended lymphadenectomy. On the other hand, the effect of stage migration notwithstanding, D2 seemed to be the only way to give hope to the small subset with a pN2-stage disease (see Fig. 3C of the same article [3]). Again, these results truthfully reflect the potential and limits of extended lymphadenectomy applied in European community hospitals in the 1980s.

One way to prove genuinely from an oncologic view point the hypothesis that an anatomically more thorough operation contributes to survival would be to conduct a similar trial only among specialized centers with negligible mortality. The Taiwanese trial, a singleinstitution study involving only three highly trained surgeons as operators, may have been exemplary in this aspect [4]. Surgical mortality in this trial was $0 \%$, and the survival benefit of a D2 resection was thus proven. To be stringent, however, this result may apply only to the Taipei Veterans General Hospital or other reputable hospitals in the Far East, whereas the results of the Dutch trial may hold true for a much greater range of regions and hospitals in the world. The potential of extended lymphadenectomy that has been strongly sug- 
gested in the Far East has now been proven, but only in an idealistic setting.

Hence, there is currently little evidence in terms of survival benefit to support the immediate introduction of D2 into the Western treatment guidelines as a standard of care. At the time when the long-term follow-up of the Dutch trial was published, an editor of a journal declared that "the debate is over" [5]; that while young surgeons should be trained to perform a complete D1 lymphadenectomy, new agents should be developed and radiation technique improved. This statement sounds convincing in a country where the incidence of gastric cancer has waned along with interest in the disease, and the vast majority of surgeries performed do not meet the criteria even of D1 [6]. Numerous promising new agents and drug combinations are, indeed, waiting in line to be tested by phase I/II trials worldwide. Given the circumstances, it comes as a surprise that several Western surgeons still postulate in their papers with enthusiasm that the lymphadenectomy issue remains open for discussion [7, 8]. Again, surgery is not merely an act of administering a given dose of drug on a given schedule, and surgeons, unlike medical oncologists, seem to have an inherent zeal to exert their efforts and tailor their surgical techniques so as to have a greater number of patients cured than their colleagues have. In this issue of Gastric Cancer, we encounter yet another group of enthusiastic surgeons, this time from Navarre, Spain [9]. After a rather uncertain start in the community hospital setting, they constituted a new team dedicated to upper GI surgery possibly under a dedicated and well-educated leader. They report a 5-year survival rate of $58.4 \%$ overall, and $26.5 \%$ among patients with metastasis to the retroperitoneal lymph nodes (secondtier nodes according to the Japanese classification). This, at a cost of two in-hospital deaths (both related to co-morbidities, not to a surgical complication), would seem highly commendable. These data reinforce the evidence provided by the Taiwanese trial that $\mathrm{D} 2$ could be meaningful in experienced hands, along with the suggestion observed in the Dutch trial that D2 could be beneficial for a subset with extensive nodal disease.

While in Belgium, I witnessed surgery performed by a Belgian surgeon whose case series published in a past issue of Gastric Cancer also deserves respect [10]. Although details of the surgical technique and devices used were different from those usually seen in Japan, the principles of surgery were the same, and I was convinced that D2 dissection performed in the West is not an illusion. However, the question remains of whether this surgeon has several followers in Belgium who would perform a similar type of surgery, both in terms of thoroughness of nodal dissection and the time taken. If not, what would be the fate of the novel Belgian gastric cancer guidelines?

A standard surgical technique for a common disease needs to be performed consistently in community hospitals without untoward consequences, and should be both easily accessible and affordable. If a given treatment is too toxic or too expensive in one community, this treatment cannot be a standard of care even if it is a winner of a phase III trial in another community. At this point, one should decide whether gastric cancer is a common disease in the Western countries. If it is, perhaps a D1 given either with perioperative chemotherapy or postoperative chemoradiation should be considered as a treatment to be highlighted in the guidelines. If it is not, one may consider treating the disease exclusively in specialized units such as those led by de Liano et al. or Collard et al. The Belgian guidelines would eventually come through, because the authors wisely emphasized this point [1].

The story is completely different in Japan, where (i) the government is obsessed with reducing the cost of medical services, (ii) good surgical skills are taken for granted by the community and are delivered at bargain prices, (iii) anticancer agents are as expensive as they are in the West, and (iv) gastric cancer is a common disease. Here, an extended lymphadenectomy should be considered as a standard and can also be regarded as the most cost-effective component of the multidisciplinary treatment. Let us hope that the deservedly leading position of the Japanese surgeons in the world as far as gastric cancer is concerned may one day be recognized as such by the general public in their own country. In the meantime, Japanese surgeons should be thankful to their colleagues in Taiwan and to the dedicated surgeons in the West for reinforcing their belief in D2 surgery.

\section{References}

1. Peeters M, Lerut T, Vlayen J, Mamboug F, Ectors N, Deprez P, et al. Wetenschappelijke ondersteuning van het College voor Oncologie: een nationale praktijkrichtijn voor de aanpak van slokdarm-en maagkanker. 2008. English version available at www.kce.fgov.be

2. Bonenkamp JJ, Hermans J, Sasako M, van de Velde CJ, Welvaart $\mathrm{K}$, Songun I, et al. Extended lymph-node dissection for gastric cancer. N Engl J Med 1999;340:908-14.

3. Hartgrink HH, van de Velde CJH, Putter H, Bonenkamp JJ, Klein Kranenbarg E, Songun I, et al. Extended lymph node dissection for gastric cancer: Who may benefit? Final results of the randomized Dutch Gastric Cancer Group trial. J Clin Oncol 2004;22:2069-77.

4. Wu CW, Hsiung CA, Lo SS, Hsieh MC, Chen JH, Li AF, et al. Nodal dissection for patients with gastric cancer: a randomized controlled trial. Lancet Oncol 2006;7:309-15.

5. Petrelli NJ. The debate is over; it's time to move on. J Clin Oncol 2004;22:2041-2. 
6. Hundahl SA, Macdonald JS, Benedetti J, Fitzsimmons T, Southwest Oncology Group and the Gastric Intergroup. Surgical treatment variation in a prospective, randomized trial of chemoradiotherapy in gastric cancer: the effect of undertreatment. Ann Surg Oncol 2002;9:278-86.

7. Schwarz RE, Smith DD. Extended lymph node dissection for gastric cancer: who may benefit? Final results of the randomized Dutch Gastric Cancer Group trial. J Clin Oncol 2005;23:54045.
8. Degiuli M, Sasako M, Ponti A, Calvo F. Survival results of a multicentre phase II study to evaluate D2 gastrectomy for gastric cancer. Br J Cancer 2004;90:1727-32.

9. Díaz de Liano A, Yarnoz C, Aguilar R, Artieda C, Ortiz H. Rationale for gastrectomy with D2 lymphadenectomy in the treatment of gastric cancer. Gastric Cancer 2008;11:96-102.

10. Collard JM, Malaise J, Mabrut JY, Kestens PJ. Skeletonizing en-bloc gastrectomy for adenocarcinoma in Caucasian patients. Gastric Cancer 2003;6:210-6. 